\title{
Ground-Based Polarimetric Remote Sensing of Dust Aerosol Properties in Chinese Deserts near Hexi Corridor
}

\author{
Hua Xu, Zhengqiang Li, Donghui Li, Li Li, Xingfeng Chen, Yisong Xie, \\ Kaitao Li, Cheng Chen, and Yuhuan Zhang
}

State Environmental Protection Key Laboratory of Satellite Remote Sensing, Institute of Remote Sensing and Digital Earth, Chinese Academy of Sciences, Beijing 100101, China

Correspondence should be addressed to Zhengqiang Li; lizq@radi.ac.cn

Received 28 February 2014; Revised 4 July 2014; Accepted 23 July 2014; Published 18 August 2014

Academic Editor: Hesham El-Askary

Copyright (c) 2014 Hua Xu et al. This is an open access article distributed under the Creative Commons Attribution License, which permits unrestricted use, distribution, and reproduction in any medium, provided the original work is properly cited.

\begin{abstract}
One-year observation of dust aerosol properties near Hexi Corridor was obtained from polarimetric measurements by groundbased sunphotometer in the county of Minqin in northwestern China from March 2012 to February 2013. We observed an annual mean AOD of $0.22 \pm 0.22$ at $0.50 \mu \mathrm{m}$ and Ångström exponents of $0.1-1.0$ fitting a bimode normal distribution centered at 0.18 and 0.50 , respectively. The effective radii of fine $(0.13-0.17 \mu \mathrm{m})$ and coarse $(2.49-3.49 \mu \mathrm{m})$ modes were found stable at all seasons together with the appearance of a third mode of particle radius at $0.4-1.0 \mu \mathrm{m}$ when AOD was larger than 0.6. It is noticeable that the real (1.5-1.7) and imaginary (0.0005 to 0.09) parts of complex refractive indices were higher than other studies performed in other desert regions of China, while single scattering albedo was relatively lower $(\sim 0.84-0.89)$ at wavelengths of $0.44,0.67,0.87$, and $1.02 \mu \mathrm{m}$. This is partially due to calcite or hematite in the soil in Minqin or the influence of anthropogenic aerosols containing carbon. Moreover, from our novel polarimetric measurement, the scattering phase function $\left(F_{11}\right)$ and degree of linear polarization for incident unpolarized light $\left(-F_{12} / F_{11}\right)$ of dust aerosols were also obtained within this deserted area.
\end{abstract}

\section{Introduction}

Dust aerosols are common natural particles suspending in terrestrial atmosphere. According to mineralogy, there are thousands of mineral species in global crust such as illite, kaolinite, gypsum, smectite, quartz, calcite, and hematite, each of which has a specific chemical composition, molecular structure, and physical morphology [1]. The abundance of minerals usually varies spatiotemporally. Dust aerosols originate from eroding rocks in deserts or arid soils and are emitted from the bare surface by updraft, then transported in a long-range way, and finally deposited by gravity or rainout. The atmospheric dust aerosols interact with light and influence the radiative forcing in global/regional scale [2]. However, knowledge of optical properties of Chinese dust aerosols is not enough and the radiative impact is poorly known as well. This is in part due to the complexity of the properties of mineral dust aerosols which depend on size, shape, and orientation [3] and in part due to the lack of longterm rigorous observation in this region.
Many researchers have improved our knowledge of dust aerosols in worldwide locations. Sokolik et al. $[4,5]$ compared refractive indices of atmospheric dust aerosols from various geographic locations and then modeled the radiative properties accounting for their compositions. Databases containing experimental scattering matrices of mineral dust particles were developed [6,7]. Apart from these highquality laboratory measurements, the optical and physical properties of dust aerosols can be retrieved by ground-based sunphotometer [8-10]. The optical properties of dust aerosols in Sahara Desert [11], Middle East [12], and Asian regions [13] were studied. In China, there were several observations in northern acrid areas such as Taklimakan Desert [14] and Hunshan Dake Desert [15].

With a goal of studying the optical and microphysical properties of dust aerosols, we deployed a ground-based sunphotometer in northwestern China. The location was surrounded by deserts where the aerosol properties and climatology of mineral dusts were thought to be obvious. We took one year observation from March 2012 to February 


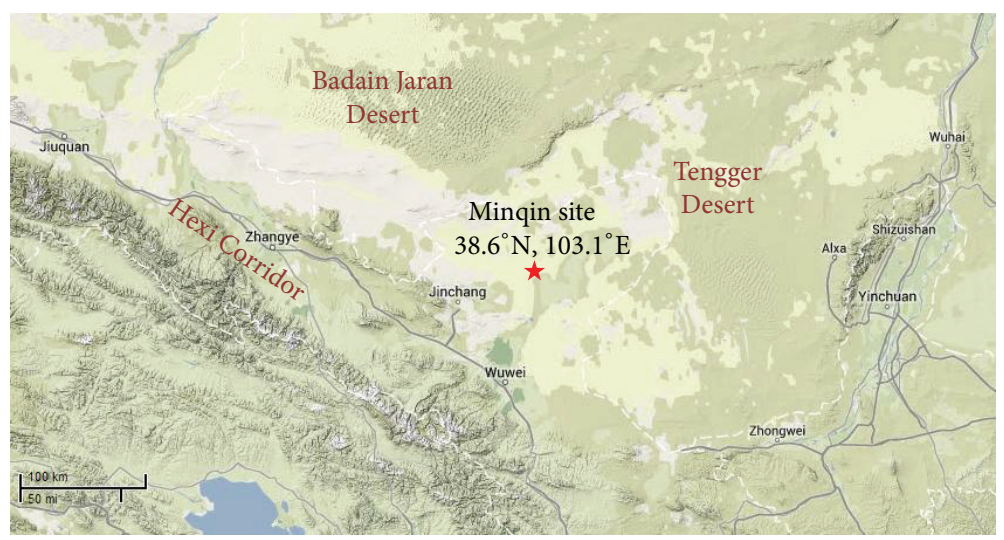

Figure 1: Geographical location of Hexi Corridor, Badain Jaran Desert, and Tengger Desert. The Minqin site $\left(38.6^{\circ} \mathrm{N}, 103.1^{\circ} \mathrm{E}\right)$ is marked as a red pentagram.

2013 and the results and analysis are shown in the following sections.

\section{Measurement and Data}

2.1. Polarimetric Sunphotometer Measurement. The sunphotometer (CIMEL CE318-DP) is a polarized instrument with nine channels of $0.34,0.38,0.44,0.50,0.67,0.87,0.93,1.02$, and $1.64 \mu \mathrm{m}$. The radiometer is capable of measuring both the direct-sun radiances and diffuse-sky radiances with a $1.2^{\circ}$ full field of view [16]. When automatic mode performs, the collimator of sunphotometer tracks the sun each 15 minutes and scans following almucantar (ALM) and solar principle plane (SPP) geometry procedures approximately each hour. For the SPP procedure, the instrument measures sky radiation at different solar elevation angles at a fixed solar azimuthal angle and large scattering angles are attainable at noon. Moreover, the sunphotometer is a new polarized version which can measure polarization at all bands by combining rotation of polarizer and filter wheels [17].

The site (referred to as Minqin site hereafter) is located at $38.6^{\circ} \mathrm{N}, 103.1^{\circ} \mathrm{E}$ in Gansu province in China (Figure 1), neighbored by Hexi Corridor. It has a peculiar geographical position because it lies on a junction of Badain Jaran Desert and Tengger Desert which are the third and fourth biggest desert in China, respectively. The climatology is a typical continental arid climate with adequate solar energy, scarce rainfall, and large evaporation. Therefore, the site is vulnerable to dust aerosols. According to meteorological records since 2006, the dust storms have happened nineteen times averagely every year. The instrument is installed in downtown which has a population of about 300,000 .

2.2. Data Processing. We use one-year measurements from March 2012 to January 2013 at Minqin site to investigate the properties of mineral dust aerosols. Unscreened measurements are frequently contaminated by clouds or obstruction. Therefore we apply cloud screening procedures which include triplet measurements (a sequence of three direct-sun measurements are taken $30 \mathrm{~s}$ apart per wavelength [16]) and check the symmetry of the ALM measurements. The latter way is suited to find whether the sky is clear because the presence of cloud would cause disparities between symmetrical pairs of ALM measurements. Following these methods, the data is upgraded from level 1.0 to 1.5. To ensure the quality, three kinds of calibrations are applied to the direct-sun measurement, diffuse-sky measurement, and polarization measurements [16-19], respectively. The uncertainty of directsun measurements makes the AOD error less than 0.01-0.02, while the uncertainty of sky radiances is estimated to be about $3 \%$. The maximum uncertainty of DOLP measurements is estimated to be less than $\sim 0.01$.

In reality, dust particles are not spherical and seldom isotropic or homogeneous. Dubovik et al. [9] established a spheroid model accounting for nonsphericity in groundbased remote sensing of aerosols. Hence, in this study we use this model for retrieving the properties of dust aerosols by spectral and angular observation of both intensity and polarization. The results will be discussed in Section 3, including AOD, Ångström exponent, size distribution, complex refractive index, single scattering albedo, phase function $\left(F_{11}\right)$, and the degree of linear polarization $\left(-F_{12} / F_{11}\right)$.

In this work, we totally select 7040 AODs and Ångström exponents records (level 1.5) out of 15309 measurements (level 1.0). For the retrieval of aerosol size distribution, complex refractive index, single scattering albedo, phase function, and the degree of linear polarization, we select only 478 records filtered by residuals threshold of $5 \%$ according to Dubovik et al. [9].

\section{Results and Discussion}

\subsection{AOD and Ångström Exponent}

3.1.1. Histogram and Monthly Variation of AOD. Following Beer-Lambert-Bouguer's law, aerosol optical depth can be derived by excluding the atmospheric molecules optical depth and gas absorption optical depth from the total optical 
depth measured by sunphotometer. About forty-five percent, 7040 records (level 1.5), of all instantaneous measurements are used for investigation in Minqin.

Figure 2 shows the frequency distribution of AODs at $0.5 \mu \mathrm{m}\left(\tau_{500}\right)$ with both relative frequency and accumulated frequency in left and right axis, respectively. The distribution is well fitted by a normal function centered at $0.22(\mu)$ with the standard deviation of $0.22(\sigma)$. It is explicit that $0.15<\tau_{500} \leq$ 0.20 occur most frequently with the probability beyond $16 \%$. When $0<\tau_{500} \leq 0.44$ (i.e., $\mu-\sigma<\tau_{500}<\mu+\sigma$ ), the accumulated frequency is beyond $80 \%$, while when $0<\tau_{500} \leq$ 0.88 (i.e., $\mu-\sigma<\tau_{500}<\mu+3 \sigma$ ), it reaches up to $97 \%$. Moreover, the distributions of AOD at other wavelengths are similar. Che et al. [14] exhibited the frequency distribution of AODs over Taklimakan Desert in China. Their histogram was fitted by two peaks; that were the mode centered at $\sim 0.23$ probably corresponding to nondust atmospheric and the mode centered at $\sim 0.50$ caused by higher mineral dust burden in atmosphere. Our average is very close to their first peak. In Figure 2 we can find that AODs within the range of 0.4-0.7 are obviously higher than the fitting curve which may correspond to their second peak. Similarly, at wavelength of $1.02 \mu \mathrm{m}$, the mean AOD is 0.21 that is close to Dubovik et al. [10] study in which the mean AOD is 0.22 in Persian Gulf and 0.17 in Saudi Arabia.

Heavy dust storms are an apparent meteorological process, but from Figure 2, it is hard to make out them because we use data of level 1.5. High-quality data and dust activities are not compatible causing a selection effect. First, large AODs corresponding to active dust events may be excluded as cloud contamination. Second, the dust storms with turbulence windy condition may cause unstable measurements. For example, in the case of heavy dust loading, due to FOV uncertainty, errors of AODs can be significant because of large forward scattering of large particles [19]. Third, due to the default digital gain of CE318 under automatic mode, the maximal AOD is suggested to be no more than 4.0. For another example, when an active dust storm happened on March 20, 2012, in Minqin, our ground-based sunphotometer only totally took down 48 records. The level 1.0 data showed that the daily average of AODs $\left(\tau_{500}\right)$ was 2.3 and the maximum even reached up to 4.7. Therefore, from this point of view, we probably lose the opportunity to investigate the heave dust aerosol burden in this area if we want to insure data quality.

The monthly variation of AOD $\left(\tau_{500}\right)$ is shown in Figure 3. The error bars stand for one standard deviation range $( \pm \sigma)$ of monthly averaged AODs. The entire observation period (from Mar. 2012 to Feb. 2013) can be divided into four seasons which are spring (from Mar. 2012 to May. 2012), summer (from Jun. 2012 to Aug. 2012), autumn (from Sep. 2012 to Nov. 2012), and winter (from Dec. 2012 to Feb. 2013). At the bottom of Figure 3, the number of monthly records (corresponding to the right coordinate) is counted. Each month has approximately equal numbers $(\sim 500-800)$ of AODs except December (83 counts) and January (23 counts). This is because we carried out instrument calibration in Beijing from Dec. 8, 2012 to Jan. 30, 2013.

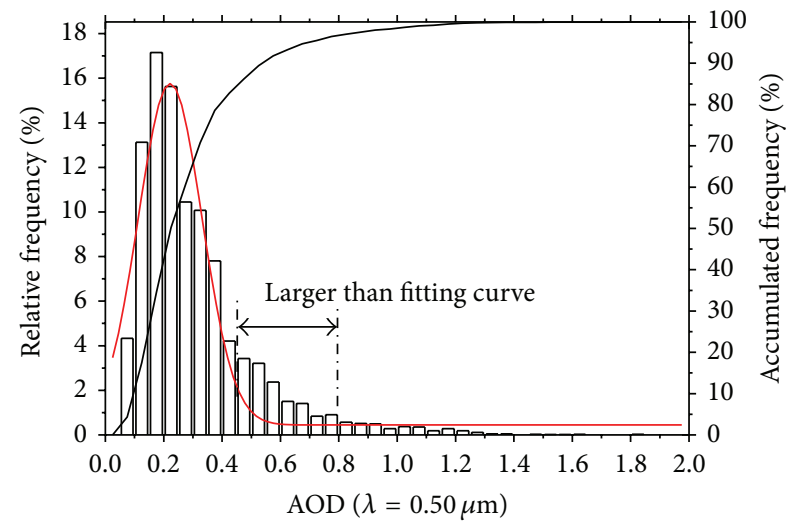

FIgURE 2: The histogram of AOD at $0.50 \mu \mathrm{m}$ in the form of relative frequency and accumulated frequency.

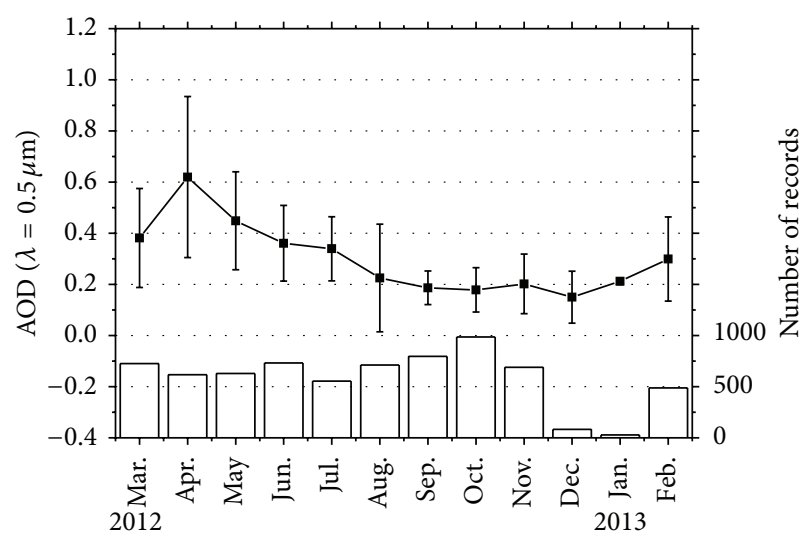

FIgURE 3: The monthly variation of AOD. The left axis corresponding to $\mathrm{AOD}$ and the right axis corresponding to number of records.

A clear pattern for monthly variation of $\mathrm{AOD}\left(\tau_{500}\right)$ can be found in Figure 3. In spring, dust aerosol load is always the heaviest among four seasons. The AOD values change from 0.4 to 0.6 with the biggest standard deviation $(\sim 0.3)$ in April. A probable explanation is that Minqin suffers from drought and active windy events in spring. From summer to autumn the AODs decrease. In October, AODs are the lowest, that is, $0.18 \pm 0.09$. Because of quiet weather, from September to November, the measurements are very stable which is reflected by small standard deviations. In winter, the AODs begin to increase slightly till the next spring. It should be noted that in January there are the fewest records and the smallest standard deviations for the sake of calibration experiment.

3.1.2. Histogram and Monthly Variation of Angström Exponent. Ångström exponent $(\alpha)$ reflects the aerosol size and its spectral dependence. The frequency histogram of Angström exponents, derived from AODs at wavelength of 0.44 and $0.87 \mu \mathrm{m}$, can be seen in Figure 4. It illustrates the main range of $\alpha$ from 0.1 to 1.0. The distribution is fitted by a bimode normal distribution centered at about 0.18 and 0.50 , comparable to Che et al. [14] results of 0.17 and 0.50 , 


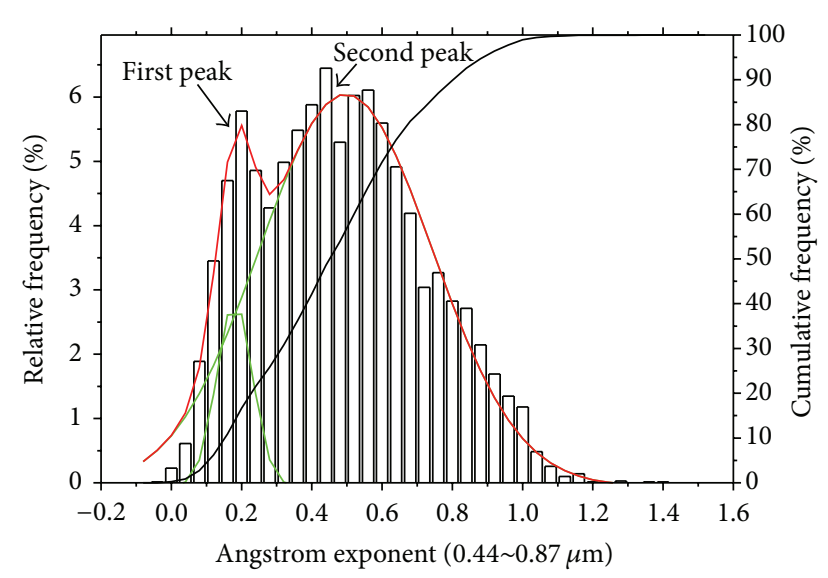

FIgURE 4: The frequency distribution of Ångström exponents $(0.44 \sim 0.87 \mu \mathrm{m})$ in the form of relative histogram and accumulated frequency.

respectively. Two peaks in Figure 4, corresponding to larger size and smaller size particles, are perhaps associated with two aerosol types in desert area. The peak 0.50 can be explained as dust particles emitted into atmosphere by wind, while another peak 0.18 may be related to suspending particles by floating dust or dust flowing. Also, the threshold is very consistent with other desert locations such as Saudi Arabia $(0.1-0.9)$ [10]. It is also found that the peak 0.18 corresponds to most of large dust aerosols $(-0.05<\alpha<0.25)$ discovered by Li et al. [11] among 5 sites in Africa arid areas.

Dust aerosols have an obvious trend of increasing AOD versus decreasing Ångström exponent. This phenomenon is caused by large particles. The monthly variation of Ångström exponent is plotted in Figure 5. Compared with Figure 3, Angström exponent behaves contrary to the AOD trend at all seasons. The minimum value of Ångström exponent is in April (0.29 \pm 0.15$)$, while the maximum value is in September $(0.64 \pm 0.22)$. In general, the size of dust aerosol is larger in winter-spring than in summer-autumn. In conjunction with Figure 4, the peak of the histogram of Ångström exponent $(\alpha \sim 0.2)$ is likely from winter-spring. When the wind blows from north to south in winter-spring season, the influence of dust particles is more noticeable resulting in lower values of Ångström exponent. Whereas, when the wind blows from south to north in summer-autumn, the anthropogenic influence is more obvious causing the values of Ångström exponent to be higher.

\subsection{Size Distribution}

3.2.1. Size Distribution versus AOD. The size of dust aerosols is normally expressed by the effective radius $\left(r_{\text {eff }}\right)$ ranging from a few nanometers to 100 microns. An ensemble of dust particles can be classified as clay $(r<1 \mu \mathrm{m})$, silt $(1<$ $r<25 \mu \mathrm{m})$, and sand $(r>25 \mu \mathrm{m})$ fractions in terms of size distribution [3]. In OPAC model [20] (tabulated in Table 1c therein), there are four mineral modes: nucleus mode, accumulation mode, mineral-transported mode, and coarse mode whose volume radii are $0.27,1.6,3.0$, and $11.0 \mu \mathrm{m}$,

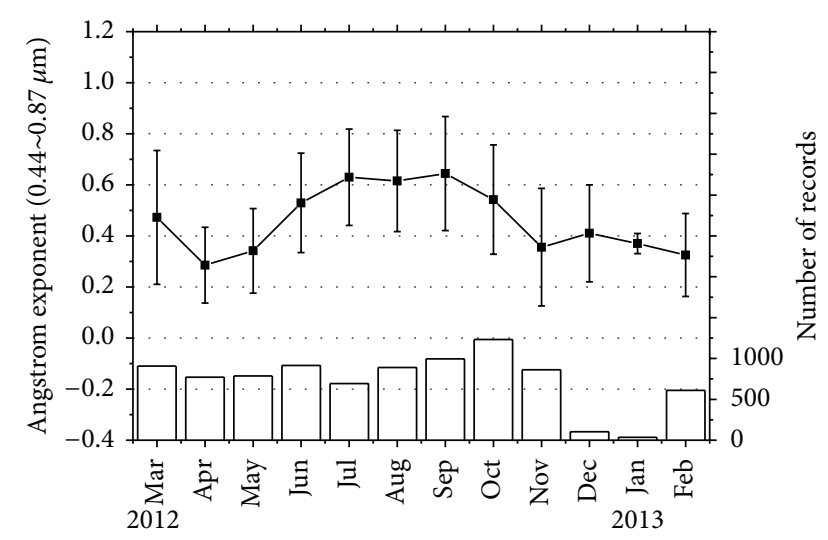

FIGURE 5: The monthly variation of Ångström exponent (0.44$0.87 \mu \mathrm{m}$ ). The left axis corresponding to Ångström exponent and the right axis corresponding to number of records.

respectively. In fact, the size distribution of dust particle is related to a few characteristics such as shape, composition, mixture manner, and AOD. For instance, tiny particles of clay are believed to stay suspended in atmosphere for a long time and then can transport further than large particles of sands. Dust aerosols may be agglomerated or aggregated through physicochemical transformation which can lead to size change.

We use a bimodal lognormal function for modeling. The size distribution is divided into twenty-two bins with radii from 0.05 to $15 \mu \mathrm{m}$ [9]. On average of all retrievals of size distributions, the effective radius of fine mode $\left(r_{f}\right)$ is $0.14 \mu \mathrm{m}$ with the standard deviation $\sigma_{f}=0.5$ while the coarse mode $\left(r_{c}\right)$ is $2.82 \mu \mathrm{m}$ with $\sigma_{c}=0.75$. Dubovik et al. [10] summarized a couple of size distributions of dust aerosols in Arabian Peninsula (Saudi Arabia and Cape Verde) and Bahrain-Persian Gulf, which were $r_{f} \sim 0.12-0.15 \mu \mathrm{m}$ and $r_{c} \sim 1.90-2.54 \mu \mathrm{m}$, respectively. Large aerosols are dominant because of $V_{C} / V_{f} \sim 2-8$. Our results agree with several previous observations $[15,21]$. However, the volume content of coarse mode in Minqin is lower than regions mentioned above $\left(V_{C} / V_{f} \sim 10-50\right)$.

In this study, we divide measurements into eight categories in terms of AODs $(\tau \leq 0.05,0.05<\tau \leq 0.1,0.1<$ $\tau \leq 0.2,0.2<\tau \leq 0.3,0.3<\tau \leq 0.4,0.4<\tau \leq 0.5$, $0.5<\tau \leq 0.6$, and $0.6<\tau \leq 1.0$ ) (Figure 6). In general, most series exhibit the dominance of large particles in dust aerosols. When AODs increase, both the concentrations of the fine and coarse modes increase. Despite changes in AODs, the aerosol size distributions are approximately consistent in shape except for $0.6<\tau \leq 1.0$. The third mode (except for fine and coarse modes) at particle radius of $0.4-1.0 \mu \mathrm{m}$ begins to appear when AODs are larger than 0.6. This change is most likely to attribute to abundance of the accumulation and mineral-transported components in dust aerosols [22].

3.2.2. Monthly Variation of Size Distribution. The monthly variation of size distribution is plotted in Figure 7 and the parameters of mean and standard deviation of effective radii 
TABLE 1: The monthly variation of effective radius, standard deviation, and volume concentration of fine mode and coarse mode.

\begin{tabular}{|c|c|c|c|c|c|c|}
\hline Month & $r_{f}(\mu \mathrm{m})$ & $r_{c}(\mu \mathrm{m})$ & $\sigma_{f}$ & $\sigma_{c}$ & $V_{f}\left(\mu \mathrm{m}^{3} / \mu \mathrm{m}^{2}\right)$ & $V_{c}\left(\mu \mathrm{m}^{3} / \mu \mathrm{m}^{2}\right)$ \\
\hline Mar. (2012) & 0.15 & 2.59 & 0.51 & 0.74 & 0.04 & 0.12 \\
\hline Apr. & 0.15 & 2.81 & 0.57 & 0.76 & 0.05 & 0.43 \\
\hline May & 0.16 & 2.64 & 0.57 & 0.76 & 0.04 & 0.14 \\
\hline Jun. & 0.13 & 3.06 & 0.51 & 0.75 & 0.05 & 0.15 \\
\hline Jul. & 0.17 & 3.49 & 0.51 & 0.77 & 0.05 & 0.09 \\
\hline Aug. & 0.14 & 3.02 & 0.46 & 0.77 & 0.02 & 0.07 \\
\hline Sep. & 0.14 & 3.01 & 0.47 & 0.76 & 0.02 & 0.07 \\
\hline Oct. & 0.14 & 2.76 & 0.51 & 0.73 & 0.02 & 0.07 \\
\hline Nov. & 0.14 & 2.49 & 0.53 & 0.72 & 0.01 & 0.07 \\
\hline Dec. & 0.15 & 2.75 & 0.50 & 0.71 & 0.01 & 0.04 \\
\hline Jan. (2013) & 0.15 & 2.93 & 0.49 & 0.66 & 0.01 & 0.15 \\
\hline Feb. & 0.16 & 2.64 & 0.53 & 0.74 & 0.01 & 0.05 \\
\hline
\end{tabular}

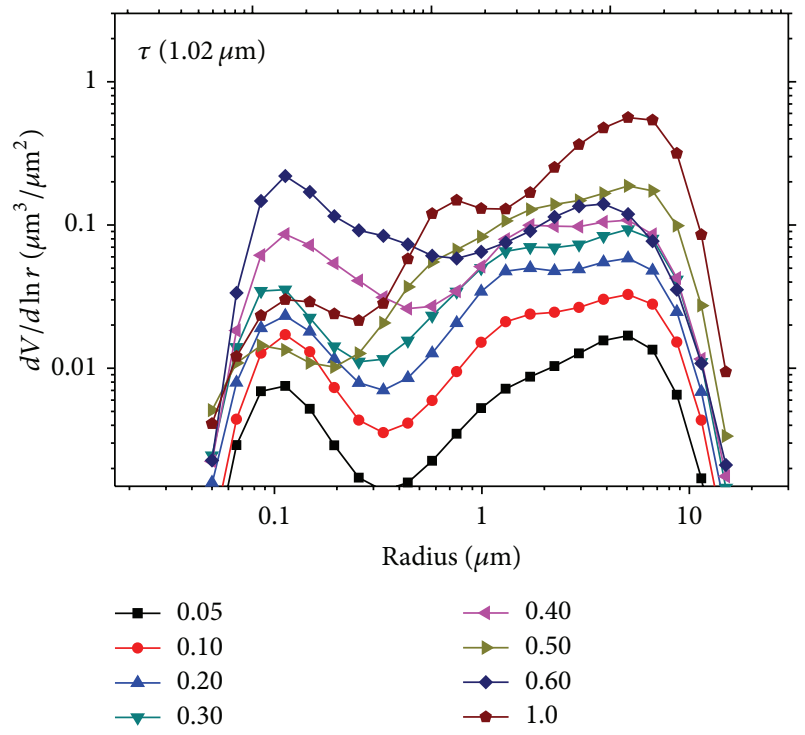

Figure 6: The size distribution of dust aerosol is divided into eight categories in terms of AODs $(\tau \leq 0.05,0.05<\tau \leq 0.1,0.1<\tau \leq 0.2$, $0.2<\tau \leq 0.3,0.3<\tau \leq 0.4,0.4<\tau \leq 0.5,0.5<\tau \leq 0.6$, and $0.6<\tau \leq 1.0)$

and volume ratios of fine mode and coarse mode are listed in Table 1. From the table, we find that both the effective radii of two modes are stable from spring to winter $\left(r_{f} \sim\right.$ 0.13-0.17 $\left.\mu \mathrm{m}, r_{c} \sim 2.49-3.49 \mu \mathrm{m}\right)$. The volume concentration of find mode $\left(V_{f}\right)$ decreases from spring to winter. The volume concentration of coarse mode $\left(V_{c}\right)$ exhibits a similar tendency only if we disregard March (0.43) and January (0.15). Moreover, $V_{c}$ is significantly high $(\sim 0.43)$ in April because of dust activities.

\subsection{Complex Refractive Index}

3.3.1. Histogram of Complex Refractive Index. The histograms of real parts of the complex refractive indices at $0.44,0.67$, 0.87 , and $1.02 \mu \mathrm{m}$ are given in Figure 8 . It should be pointed out that the threshold of real parts used in our processing is

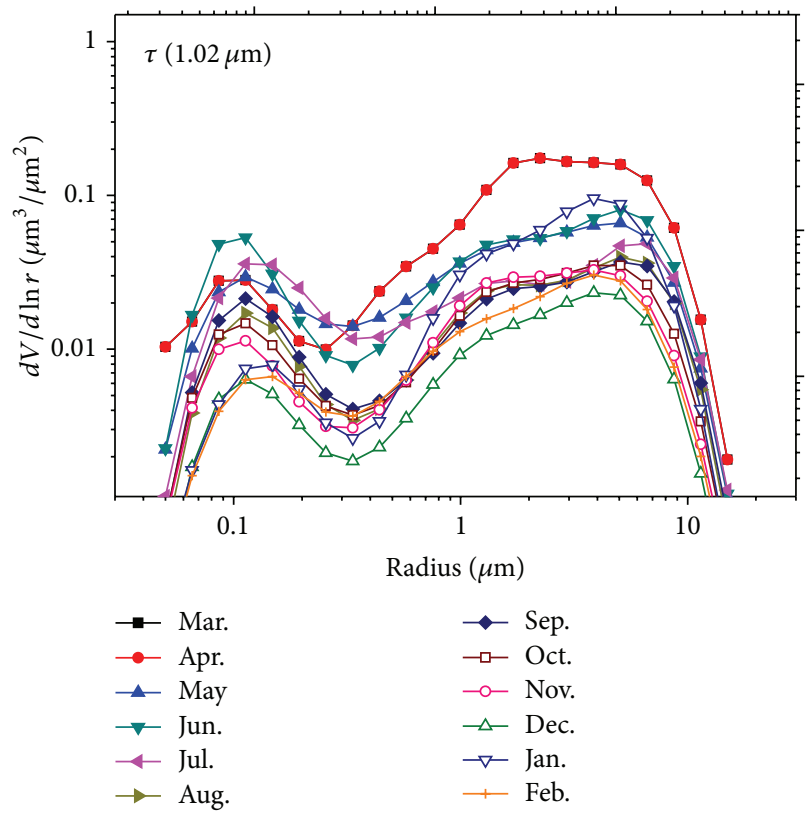

FIGURE 7: Monthly variation of size distribution of dust aerosols from Mar. 2012 to Feb. 2013.

set as 1.33-1.70, which is different from AERONET's threshold (1.33-1.60). In many models [21], the real part of dust aerosol is thought to be constantly 1.53 in visible spectrum or accompanying a slight fluctuation with a range of 0.05 in accordance with in situ measurements [4]. Nevertheless, in Figure 9, the real parts of complex refractive indices seem to be higher than expected. Additionally, the real parts of complex refractive indices in the range $(\sim 1.6-1.7)$ have a pronounced spectral variation from visible to infrared spectrum.

For imaginary parts of refractive indices, our results are given in Figure 9 with values ranging from 0.0005 to 0.09 at four wavelengths of $0.44,0.67,0.87$, and $1.02 \mu \mathrm{m}$. In the WMO model, the imaginary part of refractive index in visible spectrum is 0.008 which is thought to be larger than measurements by Dubovik et al. [10]. Otterman et al. 

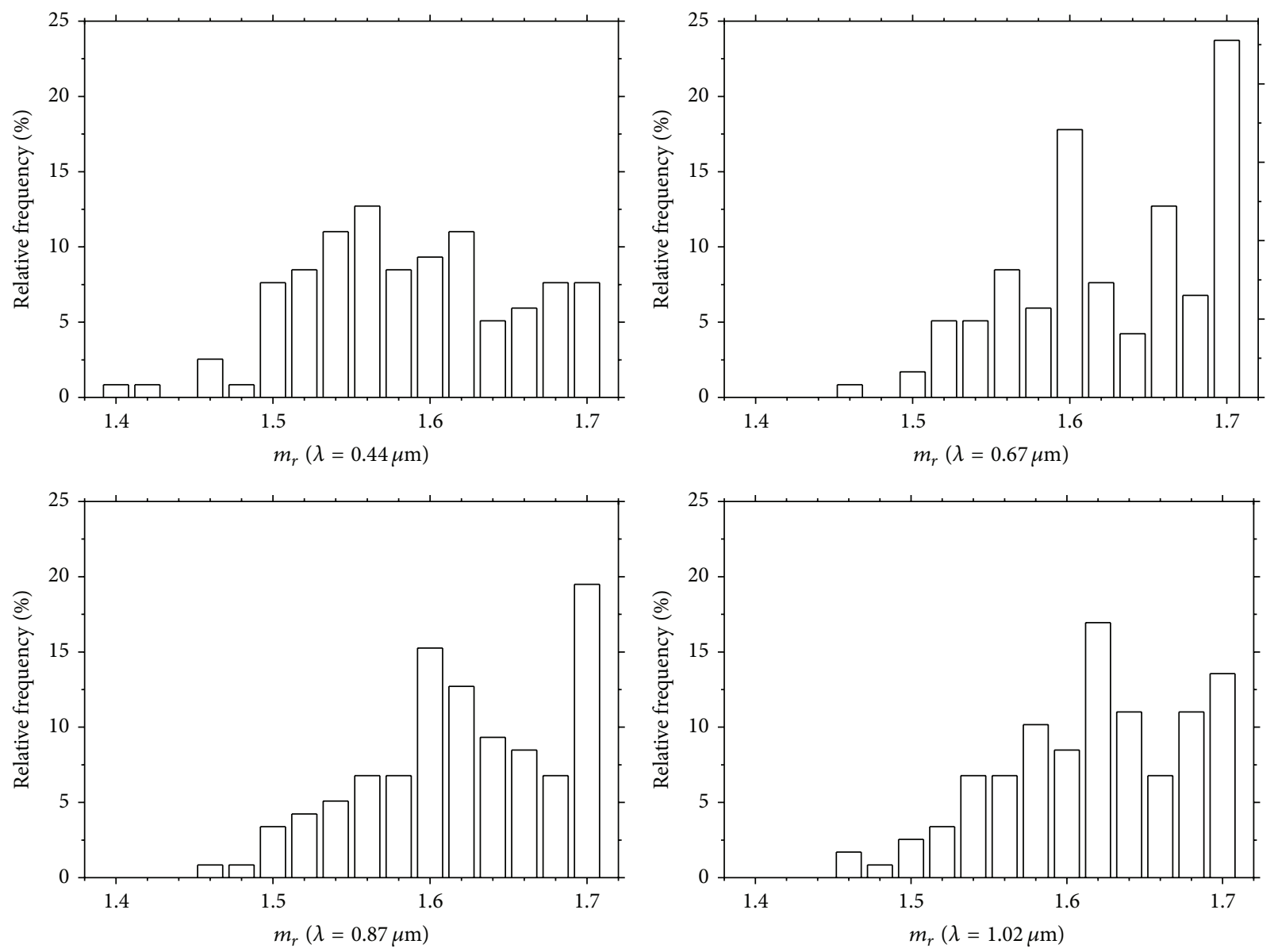

FIgURE 8: The histograms of the real part of complex refractive index for dust aerosol at $0.44,0.67,0.87$, and $1.02 \mu \mathrm{m}$.

[23] gave the value of 0.001 and sometimes 0.003 [24] when heavy dust happened. In China, Cheng et al. [15] observed a value of about $0.0007-0.0033$ at four wavelengths in Hunshan Dake Desert. Nevertheless, as explicated in Figure 9, the imaginary parts tend to be larger than previous studies. Only approximately $30 \%$ of our observations fall into the bin of 0.001-0.008.

3.3.2. Analysis of Dust Constituents. The complex refractive index of dust aerosol is relevant to its constituents. Dust aerosol is always a natural mixture of various constituents which are mainly illite, kaolinite, smectite, calcite, and quartz as major species for clays and quartz, feldspars, calcite, hematite, and gypsum for silts. The abundance of each dust mineral depends on sources, mobilization processes, and physicochemical transformations during transport. For convenience of comparison, we list complex refractive indices of various common species of dust minerals in Table 2 as well as citations. At visible wavelength the real part of mineral is about 1.4-1.6 for all aforementioned species except for limestone ( 1.655 only $o$-ray) and hematite $(\sim$ $3.0)$, while the imaginary part is very close to zero except for hematite ( 0.1-0.01). Limestone (98\% calcite), due to its property of birefringence, has two measured values of real parts, while the distribution of real parts also shows bimode. From this similarity in phenomenon, we speculated that the birefringence exists.

Looking back to our measurements, the real part is higher than 1.5. It is implicit that the limestone (calcite) may be a dominant constituent in dust aerosols in Minqin. The evidence is convincing according to the global highresolution mineralogical database of dust-productive soils [25]. The values of 1.7 may be due to our thresholds for the real part. Thus, another reason is that hematite whose real part $(\sim 3.0)$ is uniquely large than other minerals that may exist in Minqin. As Table 2 shows, the imaginary part is larger than most mineral species implying the occurrence of absorptive particles, perhaps anthropogenic aerosols due to human activities or hematite. Xiao-peng and Hai-bing [26] found that iron oxides are an important constituent of dust aerosols in Minqin, which demonstrates our speculation to some extent. Finally, the other possibility why the modeled refractive indices may turn out higher is the effect of surface roughness [3] which is not considered in Dubovik's spheroidal model.

3.4. Single Scattering Albedo. Single scattering albedo (SSA, $\omega_{o}$ ) is a synthetic optical parameter for particle scattering 

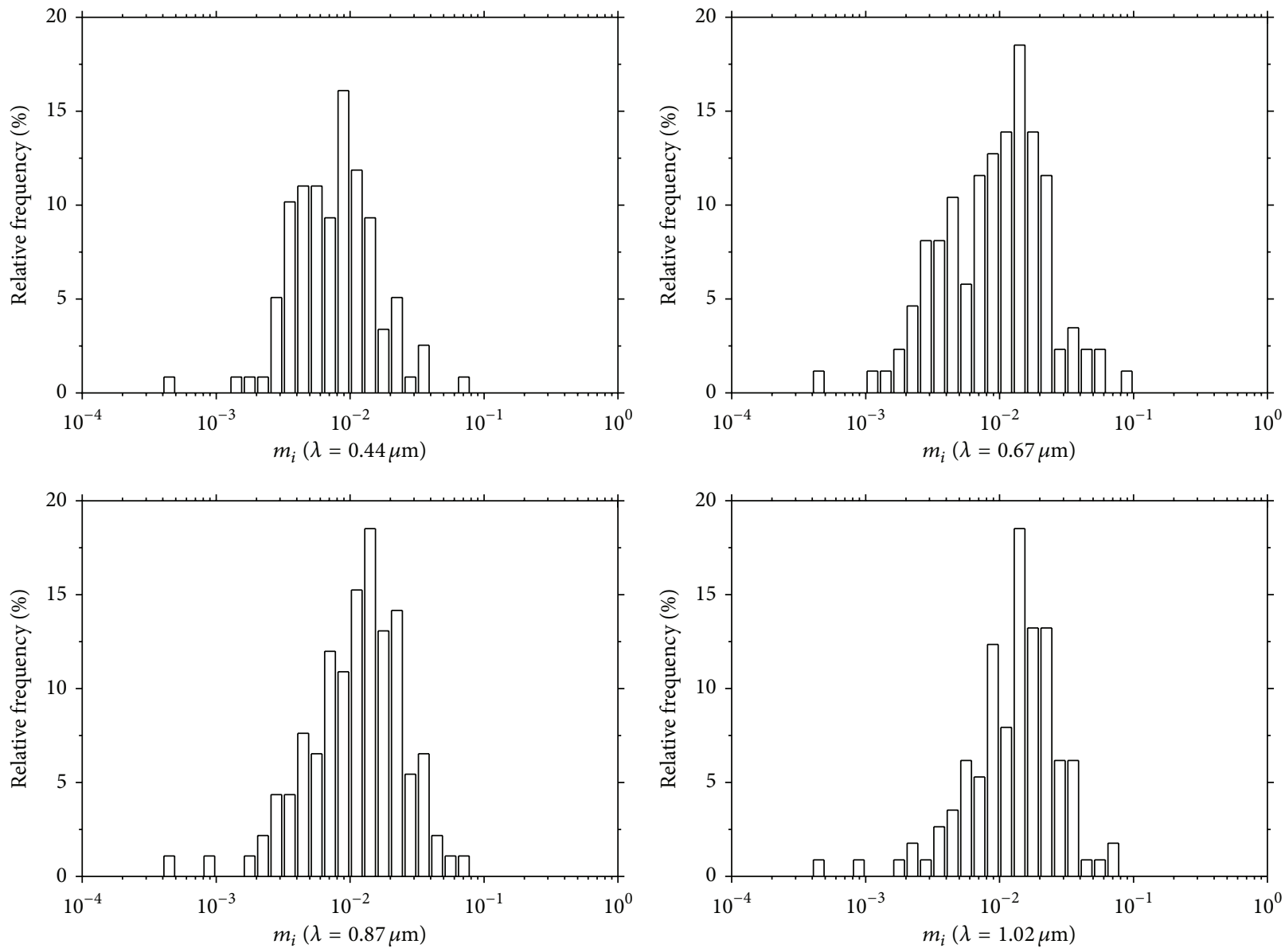

Figure 9: The histograms of the imaginary part of complex refractive index for dust aerosol at $0.44,0.67,0.87$, and $1.02 \mu \mathrm{m}$.

TABLE 2: Complex refractive indices of minerals derived from some references.

\begin{tabular}{lccc}
\hline Mineral dust & $m_{r}$ & $m_{i}$ & References \\
\hline Illite & 1.413 & 0.000773 & {$[5]$} \\
Kaolinite & 1.493 & 0.000048 & {$[5]$} \\
Montmorillonite & 1.523 & 0.000038 & {$[5]$} \\
Limestone (98\% Calcite) & 1.655 & 0 (o-ray) & {$[27]$} \\
& 1.485 & 0 (e-ray) & \\
Feldspar & $1.5-1.6$ & $0.001-0.00001$ & {$[28]$} \\
Hematite & 3.0 & $0.1-0.01$ & {$[29]$} \\
Quartz & 1.54 & 0 & {$[28]$} \\
White clay & $1.50-1.70$ & $0.00001-0.001$ & {$[30]$} \\
Green clay & $1.50-1.70$ & $0.00001-0.001$ & {$[30]$} \\
\hline
\end{tabular}

depending on its size, shape, orientation, and composition. Dubovik et al. [10] found that the SSA value of dust in situ measurement was above 0.90 at wavelengths of $0.44-0.87 \mu \mathrm{m}$. His results were significantly less absorptive than models ( 0.63-0.89 at $0.55 \mu \mathrm{m}[21])$. Generally speaking, dust aerosol is thought to be weakly absorbing except hematite. The SSAs of dust aerosols in Minqin are $0.89 \pm 0.05,0.87 \pm 0.06$, $0.85 \pm 0.07$, and $0.84 \pm 0.07$ at wavelengths of $0.44,0.67$,
0.87 , and $1.02 \mu \mathrm{m}$, respectively. The results are closed to models, but lower than Dubovik et al. [10] observation as shown in Figure 10. The figure exhibits different tendency of SSA spectrum between fine mode $(<1 \mu \mathrm{m})$ and coarse mode $(>1 \mu \mathrm{m})$ particles. For large particles, the trend of SSA increases compared to $\lambda$, agreeing well with $\mathrm{Li}$ et al. [11] statistics. In the case of nondust dominated fine aerosols, we expect $\omega_{0}(\lambda)$ to show a tendency to decrease.

According to our results, the single scattering albedo of coarse mode is obviously lower than aforementioned studies at all wavelengths. The results illustrate that dust in Minqin is likely more absorptive. In fact, the dust absorption is predetermined by the presence of hematite. Recent efforts on incorporating mineralogical composition into models of radiative properties of dust [5] emphasize that the way hematite is mixed with quartz or clay is complicated and strongly impacts the resulting absorption.

3.5. Scattering Matrix. One of the advantages in polarimetric measurement by sunphotometer is to retrieve elements from $4 \times 4$ scattering matrix, that is, Mueller matrix, which reveals important microphysical properties of an ensemble of dust aerosols. Assuming that the particles have their mirror positions in equal number and in random orientations, the matrix 

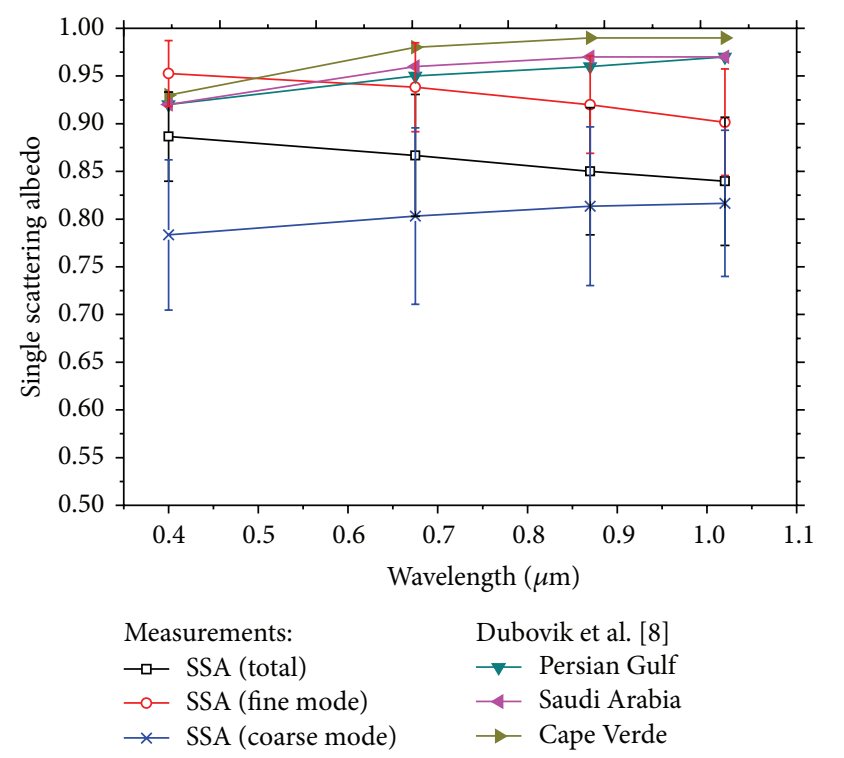

FIgURE 10: The total SSA, SSA of fine mode, SSA of coarse mode of dust aerosol at $0.44,0.67,0.87$, and $1.02 \mu \mathrm{m}$ and measurements from Dubovik et al. [10] work.

can concisely be written with six independent dimensionless elements as

$$
F=\left[\begin{array}{cccc}
F_{11} & -F_{12} & 0 & 0 \\
F_{12} & F_{22} & 0 & 0 \\
0 & 0 & F_{33} & F_{34} \\
0 & 0 & F_{34} & F_{44}
\end{array}\right]
$$

The complete scattering matrix has been investigated as a function of the scattering angle of aerosols in laboratory and published via website $[7,31]$. Two matrix elements as a function of the scattering angle, the scattering phase function $\left(F_{11}\right)$ normalized to 1 at 30 degrees, and the degree of linear polarization for unpolarized incident light $\left(-F_{12} / F_{11}\right)$ can be obtained by polarimetric ground-based observations. In the inversion algorithm [10], sky radiance and polarized radiance (the maximum scattering angle depends on solar zenith angle) are fitted simultaneously with model to yield column aerosol microphysical parameter, like aerosol size distribution, refractive index, and shape. $F_{11}$ and $-F_{12} / F_{11}$ also could be calculated from these aerosol parameters by radiative transfer model, with 83 scattering angle from 0 to $180^{\circ}$.

We average all instantaneous measurements of $F_{11}$ and $-F_{12} / F_{11}$ at the wavelength of $0.67 \mu \mathrm{m}$ and plot them with one standard deviation shown in Figure 11. Moreover, we calculate the mean values of $F_{11}$ and $-F_{12} / F_{11}$ under various conditions of Ångström exponent (three classes: $\alpha<0.25,0.25 \leq \alpha<$ 0.75 , and $\alpha \geq 0.75)$. As seen in Figure 11(a), as dust aerosols become larger (that is, $\alpha$ decreases), the forward scattering ability increases more dramatically when the scattering angle is less than $20^{\circ}$, while the curves are not obviously different in the angles of $90 \sim 160^{\circ}$. In Figure 11(b), the magnitude of degree of linear polarization decreases with the increase in particle size.

Laboratory measurements are chosen for discussions. Figure 11 shows $F_{11}$ and $-F_{12} / F_{11}$ of a sample of "white clay" measured by the IAA Cosmic Dust Laboratory, which is an ensemble of irregular particles with constituents of illite, kaolinite, montmorillonite, and quartz. Its size distribution is a single mode with $r_{\text {eff }}=2.6 \mu \mathrm{m}$ and the complex refractive index is estimated to be in the range $(1.5 \sim 1.7)-\mathrm{i}(0.00001 \sim 0.01)$ at visual wavelengths [30]. Besides we select Volten et al. [28] sample, called "average", adding to the Figure 11 because it represents an average case of dust particles consisting of feldspar, red clay, loess, Sahara sand, Pinatubo volcanic ash, Lokon volcanic ash. In Figure 11(a), $F_{11}$ agrees well with laboratory result despite the fact that the "average" is slight higher in the range $90 \sim 160^{\circ}$. Figure 11(b) shows that the shape of $-F_{12} / F_{11}$ is consistent. "White clay" is between two classes $(\alpha<$ $0.25,0.25 \leq \alpha<0.75$ ), and the corresponding Ångström exponent is estimated to be $\sim 2.5$. In contrast, "average" sample is in accordance with even smaller Ångström exponent $(\alpha<0.25)$.

\section{Conclusions}

The field observation of dust properties is still rare in desert regions of China because of difficulties in operating and maintaining precisely long-term and continuous observation in desert environment. In this paper, we provided a complete description of column dust properties at Minqin site near Hexi Corridor based on one-year measurement obtained from a ground-based polarized type of CIMEL sun-sky radiometer (CE318-DP). The study site may be attractive for various researches because of its peculiar location where both Badain Jaran Desert and Tengger Desert contribute to sources of dust aerosols.

We used the state-of-art algorithm to retrieve aerosol optical and microphysical properties, including aerosol single scattering-albedo, size distribution, complex refractive index, scattering phase function, and degree of linear polarization for incident unpolarized light (i.e., the angular distribution of the first two elements of scattering matrix). It is found that, in Minqin, an annual mean AOD was 0.22 at $0.50 \mu \mathrm{m}$ and the effective radii of fine $(0.13-0.17 \mu \mathrm{m})$ and coarse (2.49$3.49 \mu \mathrm{m})$ modes were stable at all seasons together with the appearance of a third mode of particle radius at $0.4-1.0 \mu \mathrm{m}$ when AOD was larger than 0.6. It is noticeable that the real $(1.5-1.7)$ and imaginary (0.0005 to 0.09$)$ parts of complex refractive indices were higher than other studies performed in other desert regions of China, while single scattering albedo was relatively lower $(\sim 0.84-0.89)$ at wavelengths of $0.44,0.67,0.87$, and $1.02 \mu \mathrm{m}$. This is partially due to calcite or hematite in the soil in Minqin or the influence of anthropogenic aerosols containing carbon. These dust characteristics can provide reference for different studies not only on climate change but also on environmental and ecological researches. 


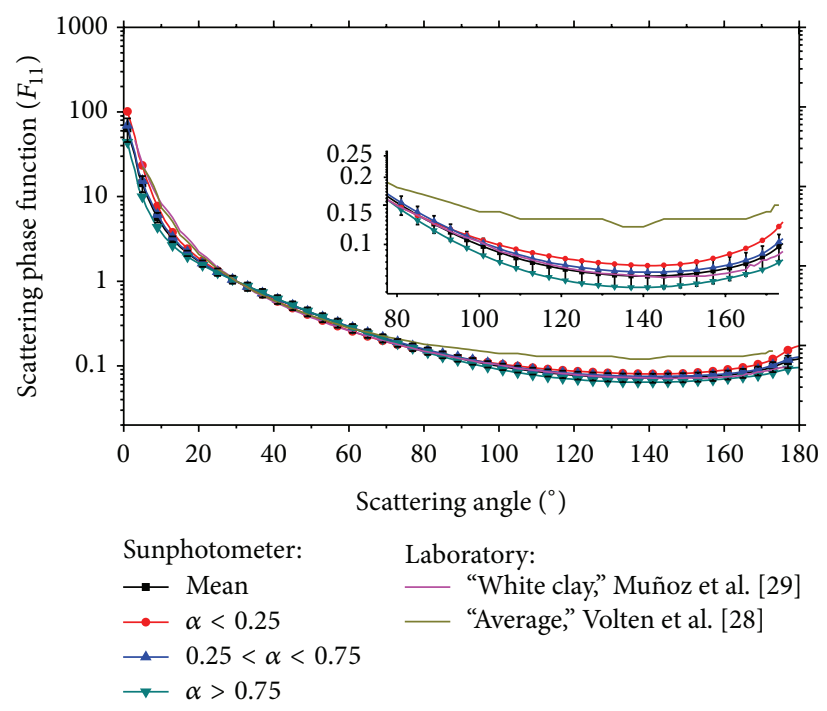

(a) $\lambda=0.67 \mu \mathrm{m}$

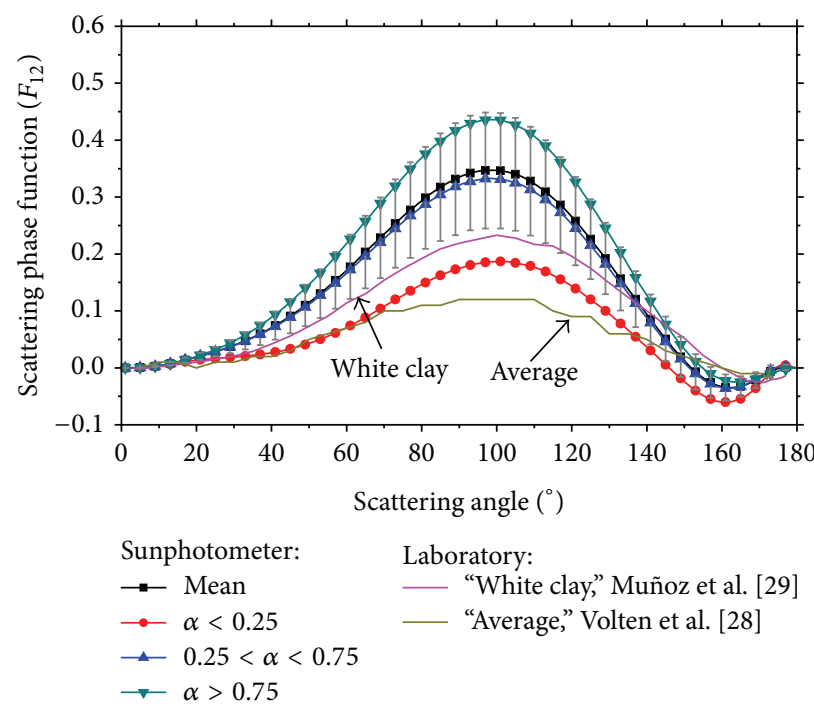

(b) $\lambda=0.67 \mu \mathrm{m}$

FIGURE 11: The scattering matrix of mineral dust aerosols in Minqin: (a) the scattering phase function $\left(F_{11}\right)$ normalized to 1 at 30 degrees and (b) the degree of linear polarization for unpolarized incident light $\left(-F_{12} / F_{11}\right)$.

\section{Conflict of Interests}

The authors declare that there is no conflict of interests regarding the publication of this paper.

\section{Acknowledgments}

The authors acknowledge the support of the National Basic Research Program of China (973 Program) under Grant 2010CB950800 (2010CB950801) and the National Natural Science Foundation of China (no. 41222007, no. 41301391). They are also grateful to Oleg Dubovik for providing retrieval of parameters of aerosols.

\section{References}

[1] T. Claquin, M. Schulz, and Y. J. Balkanski, "Modeling the mineralogy of atmospheric dust sources," Journal of Geophysical Research: Atmospheres, vol. 104, no. D18, pp. 22243-22256, 1999.

[2] V. Ramanathan, P. J. Crutzen, J. T. Kiehl, and D. Rosenfeld, "Atmosphere: aerosols, climate, and the hydrological cycle," Science, vol. 294, no. 5549, pp. 2119-2124, 2001.

[3] T. Nousiainen, "Optical modeling of mineral dust particles: a review," Journal of Quantitative Spectroscopy and Radiative Transfer, vol. 110, no. 14-16, pp. 1261-1279, 2009.

[4] I. Sokolik, A. Andronova, and T. C. Johnson, "Complex refractive index of atmospheric dust aerosols," Atmospheric Environment-A General Topics, vol. 27, no. 16, pp. 2495-2502, 1993. 
[5] I. N. Sokolik and O. B. Toon, "Incorporation of mineralogical composition into models of the radiative properties of mineral aerosol from UV to IR wavelengths," Journal of Geophysical Research D: Atmospheres, vol. 104, no. 8, pp. 9423-9444, 1999.

[6] H. Volten, O. Munoz, J. W. Hovenier et al., "WWW scattering matrix database for small mineral particles at 441.6 and $632.8 \mathrm{~nm}$," Journal of Quantitative Spectroscopy and Radiative Transfer, vol. 90, no. 2, pp. 191-206, 2005.

[7] O. Muñoz, F. Moreno, D. Guirado, D. D. Dabrowska, H. Volten, and J. W. Hovenier, "The Amsterdam-Granada light scattering database," Journal of Quantitative Spectroscopy and Radiative Transfer, vol. 113, no. 7, pp. 565-574, 2012.

[8] O. Dubovik, B. N. Holben, T. Lapyonok et al., "Nonspherical aerosol retrieval method employing light scattering by spheroids," Geophysical Research Letters, vol. 29, no. 10, pp. 541-54-4, 2002.

[9] O. Dubovik, A. Sinyuk, T. Lapyonok et al., "Application of spheroid models to account for aerosol particle nonsphericity in remote sensing of desert dust," Journal of Geophysical Research D: Atmospheres, vol. 111, no. 11, Article ID D11208, 2006.

[10] O. Dubovik, B. Holben, T. F. Eck et al., "Variability of absorption and optical properties of key aerosol types observed in worldwide locations," Journal of the Atmospheric Sciences, vol. 59, no. 3, pp. 590-608, 2002.

[11] Z. Li, P. Goloub, L. Blarel, B. Damiri, T. Podvin, and I. Jankowiak, "Dust optical properties retrieved from groundbased polarimetric measurements," Applied Optics, vol. 46, no. 9, pp. 1548-1553, 2007.

[12] T. Nakajima, G. Tonna, R. Rao, P. Boi, Y. Kaufman, and B. Holben, "Use of sky brightness measurements from ground for remote sensing of particulate polydispersions," Applied Optics, vol. 35, no. 15, pp. 2672-2686, 1996.

[13] T. F. Eck, B. N. Holben, O. Dubovik et al., "Columnar aerosol optical properties at AERONET sites in central eastern Asia and aerosol transport to the tropical mid-Pacific," Journal of Geophysical Research D: Atmospheres, vol. 110, no. 6, Article ID D06202, 2005.

[14] H. Che, Y. Wang, J. Sun, X. Zhang, X. Zhang, and J. Guo, "Variation of aerosol optical properties over the Taklimakan Desert in China," Aerosol and Air Quality Research, vol. 13, no. 2, pp. 777-785, 2013.

[15] T. Cheng, Y. Liu, D. Lu, Y. Xu, and H. Li, "Aerosol properties and radiative forcing in Hunshan Dake desert, northern China," Atmospheric Environment, vol. 40, no. 12, pp. 2169-2179, 2006.

[16] B. N. Holben, T. F. Eck, I. Slutsker et al., "AERONET-a federated instrument network and data archive for aerosol characterization," Remote Sensing of Environment, vol. 66, no. 1, pp. 1-16, 1998.

[17] Z. Li, P. Goloub, O. Dubovik et al., "Improvements for groundbased remote sensing of atmospheric aerosol properties by additional polarimetric measurements," Journal of Quantitative Spectroscopy and Radiative Transfer, vol. 110, no. 17, pp. 19541961, 2009.

[18] Z. Li, L. Blarel, T. Podvin, P. Goloub, J. Buis, and J. Morel, "Transferring the calibration of direct solar irradiance to diffusesky radiance measurements for CIMEL Sun-sky radiometers," Applied Optics, vol. 47, no. 10, pp. 1368-1377, 2008.

[19] F. Zhao, Y. Tan, Z. Li, and C. Gai, "The effect and correction of aerosol forward scattering on retrieval of aerosol optical depth from Sun photometer measurements," Geophysical Research Letters, vol. 39, no. 14, Article ID L14805, 2012.
[20] M. Hess, P. Koepke, and I. Schult, "Optical properties of aerosols and clouds: the software package OPAC", Bulletin of the American Meteorological Society, vol. 79, no. 5, pp. 831-844, 1998.

[21] W. Wmo, "Radiation commission of IAMAP meeting of experts on aerosol and their climatic effects," Tech. Rep. WCP55, World Meteorological Organization, Williamsburg, Va, USA, 1983.

[22] P. Koepke, M. Hess, I. Schult, and E. P. Shettle, Global Aerosol Data Set, Max-Planck-Institut für Meteorologie, Hamburg, Germany, 1997.

[23] J. Otterman, R. S. Fraser, and O. P. Bahethi, "Characterization of tropospheric desert aerosols at solar wavelengths by multispectral radiometry from Landsat," Journal of Geophysical Research: Oceans (1978-2012), vol. 87, no. C2, pp. 1270-1278, 1982.

[24] Z. Levin, J. H. Joseph, and Y. Mekler, "Properties of Sharav (Khamsin) dust: comparison of optical and direct sampling data," Journal of the Atmospheric Sciences, vol. 37, no. 4, pp. 882891, 1980.

[25] S. Nickovic, A. Vukovic, M. Vujadinovic, V. Djurdjevic, and G. Pejanovic, "Technical note: high-resolution mineralogical database of dust-productive soils for atmospheric dust modeling," Atmospheric Chemistry and Physics, vol. 12, no. 2, pp. 845855, 2012.

[26] J. Xiao-peng and W. Hai-bing, "Analysis of atmospheric dust composition and its influence in Hexi Corridor, Gansu," Journal of Desert Research, vol. 29, no. 1, pp. 156-161, 2009.

[27] D. D. Dabrowska, O. Muñoz, F. Moreno, T. Nousiainen, E. Zubko, and A. C. Marra, "Experimental and simulated scattering matrices of small calcite particles at $647 \mathrm{~nm}$," Journal of Quantitative Spectroscopy and Radiative Transfer, vol. 124, pp. 62-78, 2013.

[28] H. Volten, O. Muñoz, E. Rol et al., "Scattering matrices of mineral aerosol particles at $441.6 \mathrm{~nm}$ and $632.8 \mathrm{~nm}$," Journal of Geophysical Research D: Atmospheres, vol. 106, no. 15, pp. 1737517401, 2001.

[29] O. Muñoz, H. Volten, J. W. Hovenier et al., "Experimental and computational study of light scattering by irregular particles with extreme refractive indices: hematite and rutile," Astronomy and Astrophysics, vol. 446, no. 2, pp. 525-535, 2006.

[30] O. Muñoz, F. Moreno, D. Guirado, J. L. Ramos, H. Volten, and J. W. Hovenier, "The IAA cosmic dust laboratory: experimental scattering matrices of clay particles," Icarus, vol. 211, no. 1, pp. 894-900, 2011.

[31] D. B. Curtis, B. Meland, M. Aycibin et al., "A laboratory investigation of light scattering from representative components of mineral dust aerosol at a wavelength of $550 \mathrm{~nm}$," Journal of Geophysical Research D: Atmospheres, vol. 113, no. 8, Article ID D08210, 2008. 

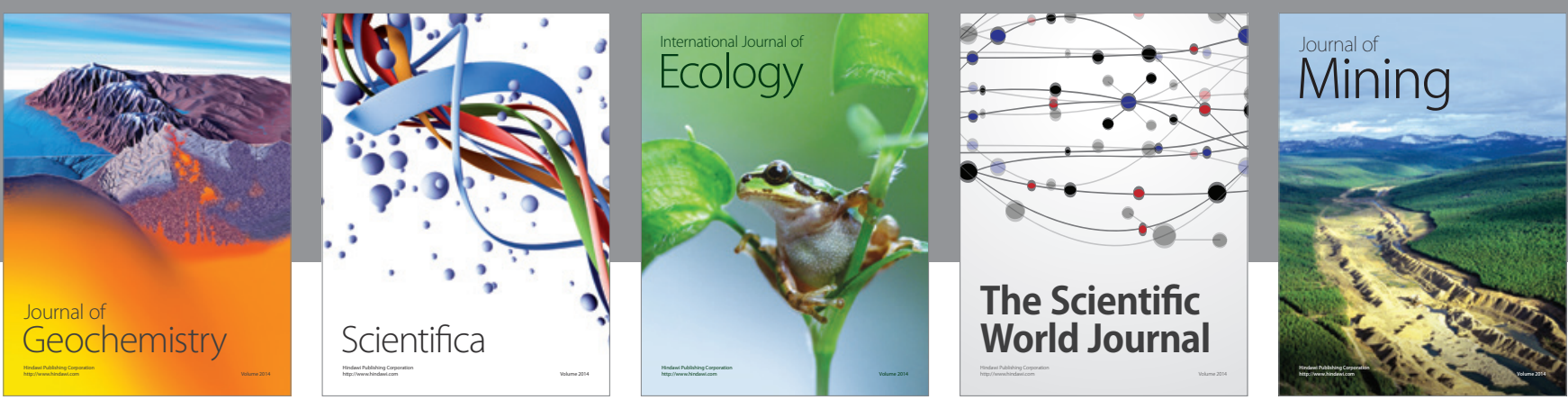

The Scientific World Journal
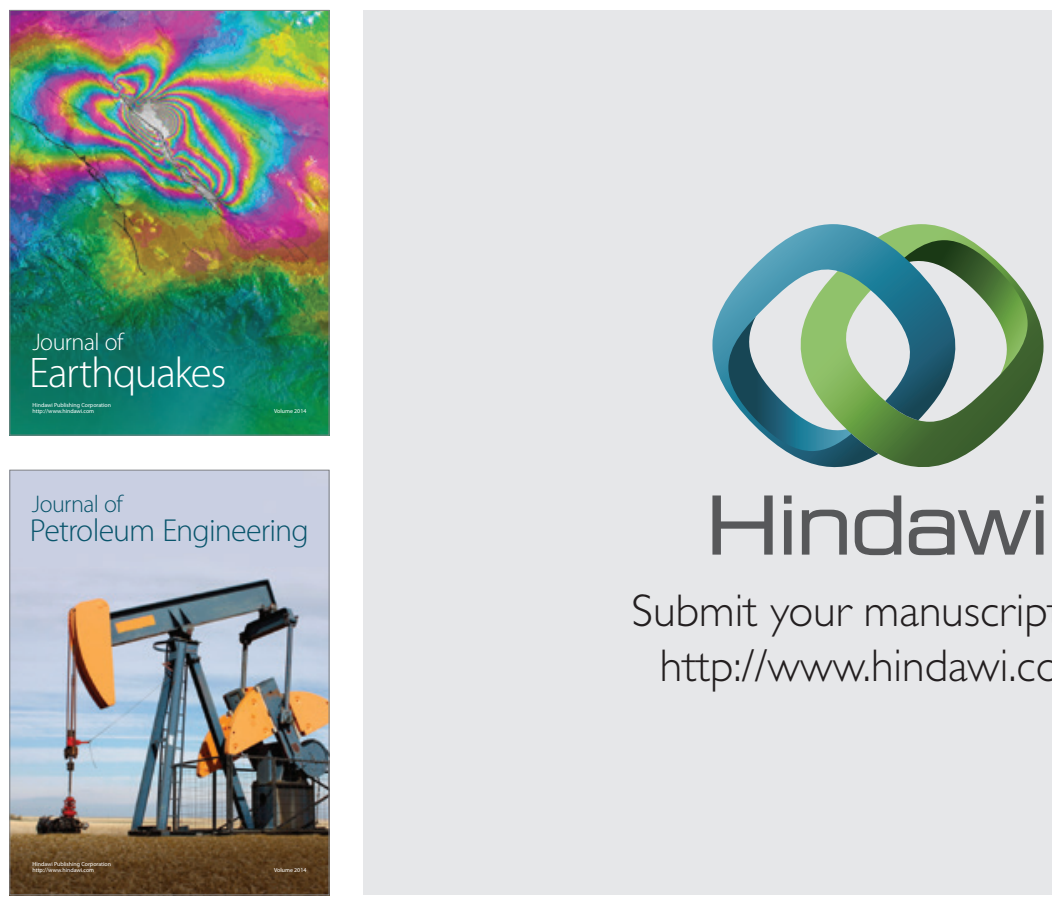

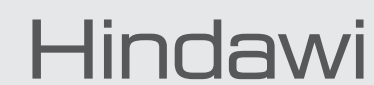

Submit your manuscripts at

http://www.hindawi.com
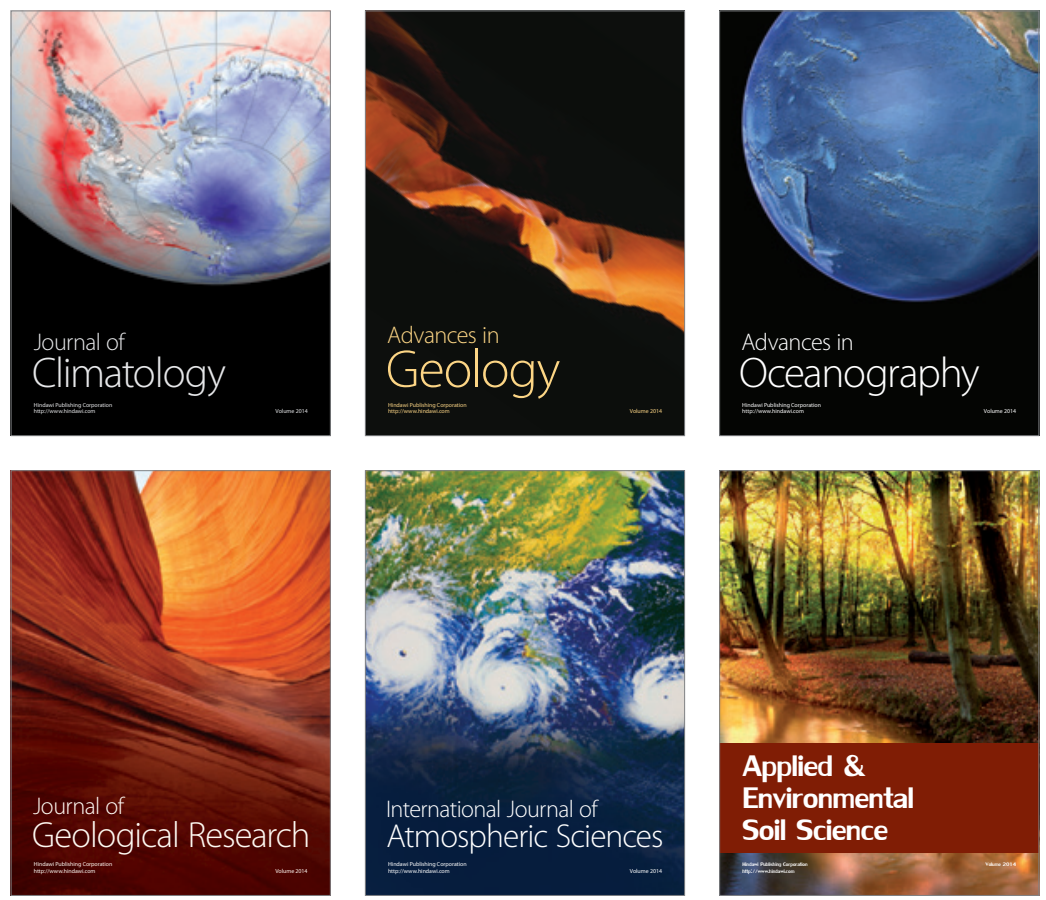
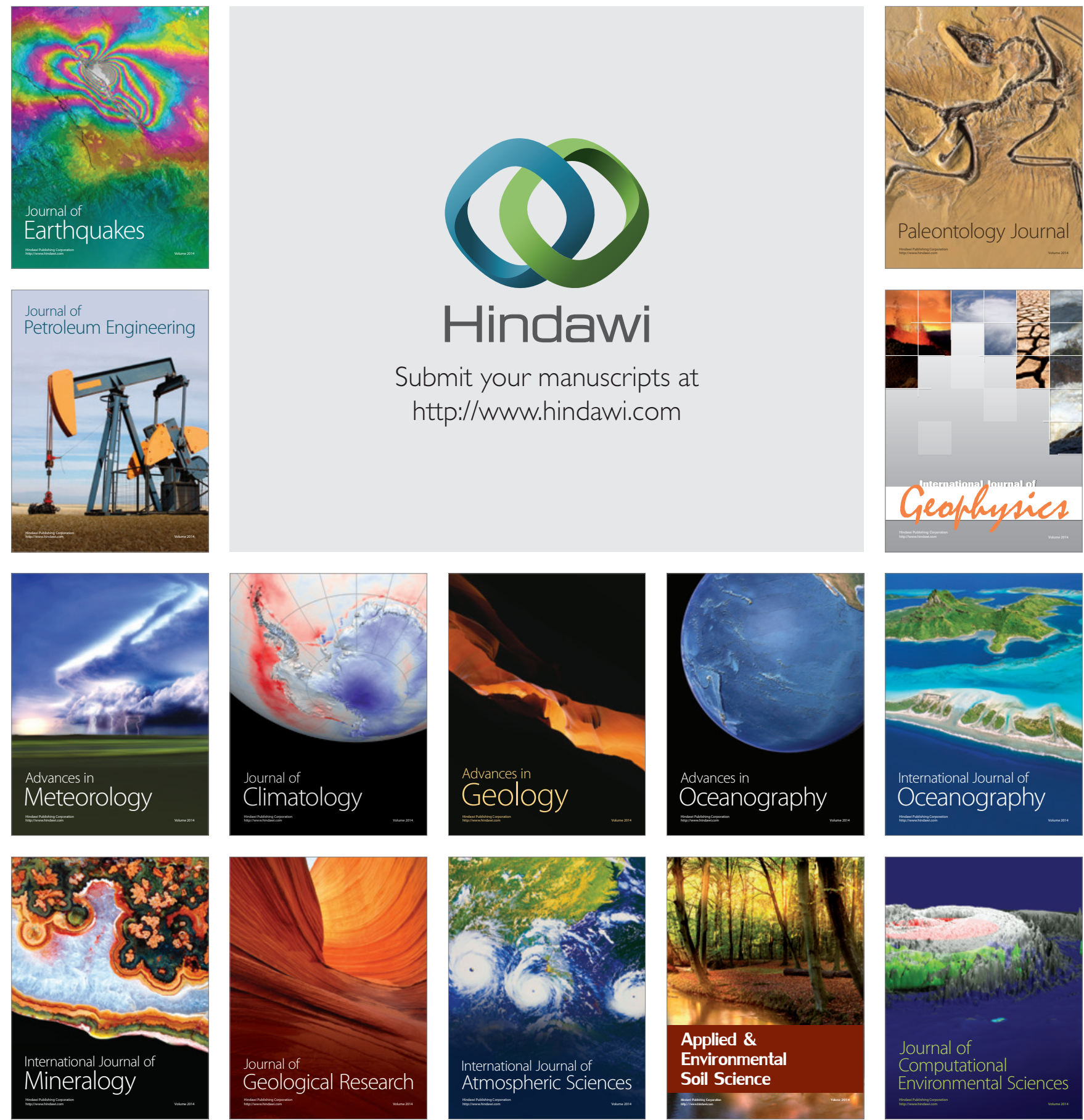